\title{
Olive Oil Traceability
}

\author{
Enzo Perri, Cinzia Benincasa and Innocenzo Muzzalupo
}

Additional information is available at the end of the chapter

http://dx.doi.org/10.5772/51796

\section{Introduction}

The market for imported, premium priced foods has increased dramatically over recent years, as consumers become ever more aware of products originating from around the world. There are many food products that are of superior quality (taste, texture, fragrance etc.) because of the locale in which they are cultivated. Environmental conditions, such as local climate and soil characteristics, combine to yield crops that exhibit specific traits. Clearly, higher quality products demands higher market prices, therefore unscrupulous traders may attempt to increase profits by deliberately mislabelling foods, or by increasing the volume of a good quality batch through adulteration with sub-standard produce.

In recent years, there has been increasing legislation to protect the rights of both the consumer and honest producers. On 2009 the European Union (EU) Member States agreed to require origin labelling for virgin and extra virgin olive oils (EC Regulation 182/2009) to defend consumers need about true characteristics and origin. To enforce these laws, a measure of the authenticity of samples must be made, most often in the form of proving the presence/absence of adulterants, or verifying geographical or cultivar origin by comparison with known and reliable samples.

The term traceability is often used in modern language, however its usage is applied for different meanings. In fact, in certain cases it is used to describe the origins of the raw materials, whilst in others to describe from which geographical region a foodstuff originates. It is also used more generically to identify a particular producer or from where it has been purchased. Many consider it as a guarantee of food safety and therefore obligatory for all food products; others however as a guarantee of quality and therefore a voluntary value.

Also the applied legislation is highly complex, with lawmakers giving different functions to traceability depending on the application and environment of the law. With the event of the food crisis in the 90's it was evident that new guidelines were urgently required to simplify and streamline the processes which could also be applied to food contamination. For this reason, the new laws of the European Union were considered as an umbrella and termed 
"General Laws for food safety" and was not applied only to food safety but also: to introduce the concept of traceability where food companies (producers, manufacturers and importers) need to guarantee to be able to demonstrate the traceability of every food, animal feed and ingredient, showing the chain from producer to consumer; create the "European Food Safety Authority" (EFSA) to unify the various commities and to make public the scientific process and risks; to strenghthen the ealry warning system adopted by European governments and the European Commission to enable rapid interventions in cases of food safety in the human and animal food chains.

In this chapter, we will only consider the "traceability" as a process that allows us to track "from downstream to upstream" the informations distributed along the olive-oil production chain, from producer to consumer (from farm to fork), and to include a evaluation of analytical methods useful in ascertaining what is claimed on the label, in according to the Regulation (CE) 178/2002.

\section{Traceability in regulation (EC) $178 / 2002$}

Since 1 January 2005, a rule has required that EU countries implement labelling and identification procedures for products sold by farmers, producers and first importers to the EU to enable and facilitate their traceability when they are put on the market. The main purpose is to be able to initiate a withdrawal and/or recall procedure for products in the event of a food crisis. The quality of traceability will enable targeted and precise withdrawals. It will also limit the extent of recalls and ensure the removal of holds on products that are not involved.

The law (EC Regulation No. 178/2002) defines traceability as: "The ability to reconstruct and follow a food, feed, a food-producing animal or substance intended to be, or to join a food or feed, through all stages of production, processing and distribution" (Article 3, paragraph 15).

Many use the terms tracking and traceability synonymously. In reality, these two terms identify two inverse processes:

- tracking identifies the location of a product from upstream to downstream in the chain and at every stage of the journey;

- traceability or tracing is the inverse process, which allow us to gather the information previously issued. It is evident that the two processes are strongly related and based on the same system.

Traceability does not refer to the production of a generic good. It makes each unit of production physically identifiable, managing production processes that are determined by "lots", and manage traceability means identifying each group of products and following the path.

It is necessary to record information relating to inputs (products and companies), processing (product lots, which lots and what end products) and outflows (products/companies /clients). The key is to define the composition of a set of products that have undergone the same process of transformation. 
Moreover, the amount of information that identifies a batch may vary and of course the complexity of the whole system increases with what information the company chooses to include in the identification of a lot.

Internal traceability, then, helps to express the internal procedures of each company to trace the origin of materials used.

The label is the instrument through which information is transferred to consumers. It's easy to understand why this essential requirement is effective.

Finally, the information given in the production lot should be able to trace all the links along the chain, back to the first producer and/or supplier of the product or substance to whom it belongs. Traceability chain is an inter-company process, resulting from internal processes of every operator in the industry. These systems should be linked by efficient information systems. It is not governed by a single person in the chain, the relations between the operators allow the tracing of the chain.

\section{Analytical methods for the traceability of extra virgin olive oil}

The increase in the demand for high-quality olive oils has led to the appearance in the market of olive oils elaborated with specific characteristics. They include oils of certain regions possessing well-known characteristics, that is, olive oils with a denomination of origin, or with specific olive variety composition, that is, coupage or monovarietal olive oils. Monovarietal olive oils have certain specific characteristics related to the olive variety from which they are elaborated (Montealegre et al., 2010). However, coupage olive oils are obtained from several olive varieties to achieve a special flavor or aroma.

The appearance of denominations and protected indications of origin has promoted the existence of oils labeled according to these criteria. Regulation 2081/92, to promote and protect food products, created the systems known as:

- $\quad$ Protected Designation of Origin (PDO);

- $\quad$ Protected Geographical Indication (PGI);

- “Traditional Speciality Guaranteed" (TSG).

An olive oil with a PDO denomination requires meeting precise definition of several parameters such as cultivar, geographical origin, agronomic practice, production technology, and organoleptic qualities (Giménez et al., 2010), and all of these parameters have to be investigated to study its traceability and to certify its quality. The introduction of certifications of origin and quality for virgin olive oil as PDO makes necessary the implementation of traceability procedures.

Any research dealing with olive oil traceability is focused on investigating the botanical or geographical origin. In both cases, the selection of the markers (compounds with discriminating power) to be studied is complicated because the composition of extra virgin olive oils is the result of complex interactions among olive variety, environmental conditions, fruit ripening, and oil extraction technology (Araghipour et al., 2006). The verification of the 
cultivars employed to produce an olive oil sample may contribute to address the oil origin. This fact may have commercial interest in the case of monovarietal olive oils or olive oils with PDO because these high-quality olive oils may be adulterated by other oils of lower quality, using anonymous or less costly cultivars (Sanz-Cortes et al., 2003).

Unfortunately, morphological traits have been difficult to evaluate, are affected by subjective interpretations, and are severely influenced by the environment and plant developmental stage (Japon-Lujan et al., 2006). Nowadays, several efforts have been focused on the investigation of one or several compounds present in olive oils usable to differentiate olive varieties (Sanz-Cortes et al., 2003).

Compositional markers (substances that take part of the composition of the olive oils) include major and minor components. Major components such as sterols, phenolic compounds, volatile compounds, pigments, hydrocarbons, tocopherols, fatty acids and triglycerides may provide basic information on olive cultivars. Minor components can provide more useful information and have been more widely used to differentiate the botanical origin of olive oils (Howarth and Vlahov, 1996; Lanteri et al., 2002).

In recent years, there has been increasing legislation to ensure consumer confidence and to protect the rights of both the consumer and honest producers.

It is of great importance the development of analitycal methods to verify the correspondence between what is stated on the label and what is contemplated in the documents (EC Regulation 182/2009 and Reg. 834/2007) in relation to the production of olives and extra virgin olive from organic farming. Moreover, to enforce these laws, a measure of the authenticity of samples must be made, most often in the form of proving the presence/absence of adulterants, or verifying geographical or cultivar origin by comparison with known and reliable samples. The latter method often includes the use of multivariate statistical techniques such as principal components analysis, linear discriminant analysis, canonical variance analysis and partial least squares regression to investigate sample data (Giménez et al., 2010).

\subsection{Chromatographic techniques for the traceability of olive oil}

In the last decade, gas chromatography (GC), high performance liquid chromatography (HPLC), supercritical fluid chromatography (SFC), and capillary electrophoresis (CE) have been widely used in the authentication analysis of olive oil. The fat, sterols, protein, carbohydrate or other natural compound profiles (Aparicio-Ruiz, 2000; Benincasa et al., 2003; Vichi et al., 2005; Lopez Ortiz et al., 2006; Temime et al., 2006; Canabate-Diaz et al., 2007; Cavaliere et al., 2007; Haddada et al., 2007; Vichi et al., 2007; Lazzez et al., 2008) have been used to provide species and geographical differentiation. In several cases, enantiomeric composition has been utilised (Rossmann et al., 2000). These methods of discrimination rely on samples of different species and/or different geographical origin having different chemical compositions. This is not always the case, samples from the same location have been found to contain different components and conversely samples from different regions may display identical chemical composition. 
Detectors usually used, in combination with chromatographic techniques (GC and HPLC), may be more or less selective and sensitive, but lack information about the identity of compounds. Therefore, the coupling of chromatographic techniques and mass spectrometry (MS) overcomes this drawback (Cavaliere et al., 2007; Lazzez et al., 2008).

MS is a sensitive and selective detector, sometimes allowing preparation steps to be avoided. GC-MS is a robust technique, used routinely in many laboratories for food analysis; for example for the determination of aroma compounds and pesticide analysis. More recently, LC coupled to quadrupoles, magnetic sectors or time-of-flight (TOF) detectors, has also had a great expansion into the field of food analysis.

The recently introduced spray methods (ESI) have fostered qualitative and quantitative analysis of medium to high polar analytes by mass spectrometry. The designing of ion source houses for ESI has also fostered the rediscovery of atmospheric pressure ionization (API) methods such APCI where the chemical ionization (CI) is achieved at atmospheric pressure. Both techniques produce soft ionization, but additional fragmentation can be achieved by performing in-source collision induced dissociation (CID) in tandem or trap instruments. MS/MS in space (tandem, sectors, quadrupoles, TOFs, etc.) and in time (traps) provide additional and unique information on the structure of analytes. ESI is useful for polar and ionic solutes ranging in molecular weight from 100 to $150 \times 10^{3}$ dalton. APCI is applicable to non-polar and medium polarity molecules with a molecular weight from 100 to 2000 dalton. Although the choice of the right interface, as well as the detection polarity are based mostly on the compounds polarity and thermal stability, and the HPLC operating conditions, many classes of compounds can give good response with both ionization techniques. In certain circumstances both positive and negative ionization modes are needed, while in most of the cases the choice of only one operation mode is enough. The number of applications of HPLC-API-MS to food analysis has rapidly increased in recent years. ESI is much more widespread than APCI, but for both techniques the trend is towards an increase in the number of applications (Sindona et al., 1999; 2000; Di Donna et al., 2001).

\subsection{Stable isotope techniques for the traceability of olive oil}

Stable isotope techniques enable differentiation of chemically identical substances through alterations in their isotopic fingerprint, and have been used in authenticity studies for many food products. The isotopic composition of light elements (lighter than calcium) in plant material can vary depending on location but, the dominant factor is the influence of latitude on the fractionation of the elements in groundwater.

Fractionation occurs during physical processes such as evaporation. Lighter isotopes evaporate very slightly faster than their heavier counterparts, therefore in warmer regions where the amount of evaporation is higher, the isotopes are fractionated to a greater degree. The discrimination between isotopes in such physical processes is only significant for light elements, with a high relative mass difference between the isotopes. Thus hydrogen ratios, measured by site-specific natural isotope fractionation nuclear magnetic resonance (SNIF$\mathrm{NMR}$ ), and carbon, nitrogen, oxygen and sulphur isotope ratios measured by isotope ratio mass spectrometry (IRMS) have been applied to the authentication of foods. 
The elemental composition of vegetation reflects (to a certain extent) that of the soil in which it has grown (Kelly et al., 2002) which in turn will depend on the topography, geology and soil characteristics. Therefore, no two countries will have identical soil maps, and the concentration of elements in food product, can then be used to assign their geographical origin. As with other methods of authentication, a database of samples of known origin must be available, against which unknown samples can be compared. The most useful elements for the assignment of origin are those that are not homeostatically controlled. Elements such as $\mathrm{K}, \mathrm{Ca}$ and $\mathrm{Zn}$ are actively absorbed by organisms and will therefore be present in samples at similar levels, regardless of the environmental conditions experienced.

Elements that have no role in normal physiological processes, such as the rare earth elements (REEs) and the heavy metals, are passively absorbed and the concentration of these elements in an organism will strongly reflect the environmental levels to which the organism has been exposed.

\subsubsection{Inductively coupled plasma mass spectrometry technique}

Several studies have used multi-element concentration profiles in the determination of food authenticity, either alone or in combination with chromatographic or stable isotope ratio data. Elemental concentrations were determined by atomic absorption spectroscopy (AAS), inductively coupled plasma - atomic emission spectroscopy (ICP-AES) or inductively coupled plasma - mass spectrometry (ICP-MS) (Dugo et al., 2004; Benincasa et al., 2007; Cindric et al., 2007).

Several trace elements have variable natural isotopic abundance due to the decay of radioactive isotopes. These include $\mathrm{Li}, \mathrm{B}, \mathrm{Cu}, \mathrm{Sr}, \mathrm{Nd}, \mathrm{Hf}, \mathrm{Pb}$ and $\mathrm{U}$. The composition and age of the local rocks dictates the abundance of the radioactive precursors and their daughter species. Elements are taken up into plants in the same isotopic proportions as they occur in the soil and in precipitation.

Therefore isotope ratios in plant-derived food products depend on the geology of the region in which the source crop was grown, and are different in produce of different geographical origin. There have, however, been relatively few reports of the use of heavier stable isotope ratio measurements for the authentication of foodstuffs. For many years thermal ionization mass spectrometry (TIMS) was the only technique capable of performing isotope ratio measurements with sufficient precision to allow geographical assignment of food products based on trace element isotopic composition. Samples for TIMS analysis must be loaded in the form of the pure element, meaning that extensive sample preparation is required if this technique is to be applied.

ICP-MS is now a well established technique for isotopic trace element determinations. ICPMS allows rapid analysis of a large range of sample types, requires minimal sample preparation and due to the ionising power of the ICP, can be applied to a wider range of elements than TIMS. The precision of isotope ratio analyses by ICP-MS has only recently matched that achievable by TIMS, through the application of double focusing mass analysers coupled to multi-collector detection arrays. The increasing availability of multi- 
collector ICP-MS is likely to lead to wider application of heavier stable isotope ratio measurements to the authentication of food products.

\subsection{2. ${ }^{13} \mathrm{C}$ compound-specific isotope analysis}

One of the most powerful techniques to be used in food authenticity studies is stable isotope ratio mass spectrometry (SIRMS). SIRMS has found application in the authentication of a wide range of foodstuffs, especially for the detection of added cane sugar in fruit juices (Bricout and Koziet, 1987), wines (Dunbar and Schmidt, 1984), spirits (Parker et al., 1998), honey (White et al., 1998) and to detect the adulteration of flavour compounds with synthetic analogues (Culp and Noakes, 1990). The majority of the reported research has focused on bulk or global stable carbon isotope ratios $\left({ }^{13} \mathrm{C} /{ }^{12} \mathrm{C}\right)$.

Approximately $98.89 \%$ of all carbon in nature is ${ }^{12} \mathrm{C}$ and $1.1 \%$ is ${ }^{13} \mathrm{C}$. The amount of ${ }^{13} \mathrm{C}$ present in a sample is expressed as a ratio to the amount of ${ }^{12} \mathrm{C}$ present, relative to an international standard using the $\delta$ notation. This notation has the units per mil (\%o). The $\delta^{13} \mathrm{C}$ value of plants varies because of isotopic fractionation during physical, chemical and biological processes.

Photosynthetic fixation of $\mathrm{CO}_{2}$ by plants takes place by three different routes, depending on the nature of the plant. Most terrestrial plants photosynthesise using the Calvin or C3 pathway in which $\mathrm{CO}_{2}$ is fixed via the carbon cycle to from a three-carbon compound. Some plants, mainly tropical grasses, such as maize and sugar cane use the Hatch-Slack or C4 pathway in which the initial "Hatch-Slack" step is via a dicarboxylic acid, a four carbon compound. A third photosynthetic class of plants uses the CAM (Crassulacean acid metabolism) pathway.

Typical CAM plants are succulents and are of minor importance in the oleochemical industry. In the C3 pathway carbon dioxide is fixed via the carboxylation of ribulose-1,5diphosphate to form phosphoglyceric acid (a 3-carbon molecule). This enzyme catalysed reaction discriminates against ${ }^{13} \mathrm{C}$ and so proceeds with a relatively large isotope effect (O'Leary, 1981). This means that less ${ }^{13} \mathrm{CO}_{2}$ is incorporated into $\mathrm{C} 3$ plants than into $\mathrm{C} 4$ plants. C3 plants have bulk $\delta^{13} \mathrm{C}$ values in the range -24 to $-30 \%$ o whereas $\mathrm{C} 4$ plants have bulk $\delta^{13} \mathrm{C}$ values from -9 to $-14 \%$.

Olive oil shows a $\delta^{13} \mathrm{C}$ values of $28.7 \%$.

The most widely used technique to assess the authenticity of edible oils is to measure the fatty acid composition. However it is not always possible to detect adulteration by this technique because of the natural variation in fatty acid profiles and because blends of oils with fatty acid compositions similar to the authentic oil may be prepared relatively easily. A more sophisticated approach is to determine the fatty acid composition at the 2 position of the triacylglycerol, since this is known to differ from the overall fatty acid composition. Woodbury et al., (1998) used this technique to obtain the compound-specific $\delta^{13} \mathrm{C}$ values of the fatty acids specifically at the 2-position of the triacylglycerol. 
Royer et al., (1999) examined 188 olive oils produced mainly in Greece during 1993 to 1996. The concentration and $\delta^{13} \mathrm{C}$ value of individual fatty acids present in the olive oils were determined by gas chromatography and GC-C-IRMS respectively. The results were examined in terms of geographical, temporal, and botanical factors. French and Italian olive oils were securely classified at the $99.9 \%$ confidence interval using the $\delta^{13} \mathrm{C}$ values of the principal fatty acids palmitic (C16:0), oleic (C18:1) and linoleic (C18:2). Regional classifications for the Greek olive oils were also achieved on the basis of differences in the ${ }^{13} \mathrm{C}$ abundance of oleic acid compared to linoleic acid and palmitic acid.

Glycerol is a primary metabolite in plants. It is nominally present in its ester form as glycerolipids in fats and oils (Kiritsakis and Christie, 1999). Glycerol is bio-synthesised relatively early in the lipidic metabolic pathway compared to fatty acids (Weber et al., 1997; Harwood and Sánchez, 1999).

Consequently, it may be expected that the isotopic distribution in glycerol is a better indicator of the botanical and environmental influences on any given plant. A number of compound specific IRMS studies on glycerol have been performed, some of which include data derived from vegetable oils.

\subsection{3. ${ }^{18} \mathrm{O}$ and ${ }^{2} \mathrm{H}$ pyrolysis CF-IRMS}

The abundance of the stable isotopes oxygen-18 $\left({ }^{18} \mathrm{O}\right)$ and deuterium $\left({ }^{2} \mathrm{H}\right)$ are particularly interesting isotopic probes for both botanical and geographical identification of a variety of different food products. The primary source of all organic hydrogen and oxygen is the hydrosphere. The meteoric water that has passed through the meteorological cycle of evaporation, condensation and precipitation finally constitutes the groundwater and exhibits a systematic geographical isotope variation. Decreasing temperatures cause a progressive heavy-isotope depletion of the precipitation when the water vapour from oceans in equatorial regions moves to higher latitudes and altitudes. Evaporation of water from the oceans is a fractionating process that decreases the concentration of the heavy isotopomers of water $\left({ }^{1} \mathrm{H}^{2} \mathrm{H}^{16} \mathrm{O},{ }^{1} \mathrm{H}^{1} \mathrm{H}^{18} \mathrm{O}\right)$ in the clouds compared to the sea. As the clouds move inland and gain altitude further evaporation, condensation and precipitation events occur decreasing the concentration of deuterium and oxygen- 18 .

Consequently, the ground water reflects this isotopic gradient from the coast to inland areas. For land plants, a further pre-assimilation affects the isotopic composition of the water substrate. The hydrogen and oxygen present in plant material originates from the water taken up by the roots. The water is transported through the plants xylem system. The isotopic composition of the xylem water is the same as that of water taken in by the roots, and the water is taken into the leaves without a change in isotopic composition. Evapotranspiration of water through the leaf enriches the remaining water in the heavier isotopomers. Therefore, it is expected that growing regions with relatively low humidity, where the rate of evaporation from the leaf is higher, result in plant materials with relatively enriched $\delta^{2} \mathrm{H}$ and $\delta^{18} \mathrm{O}$ values. 
Over the past 5 years there has been a marked increase in the use and application of ${ }^{2} \mathrm{H}$ and ${ }^{18} \mathrm{O}$ stable isotopes in many areas of food research. This has been facilitated by recent developments in on-line gas preparation devices that proceed by high temperature pyrolysis of organic products and the availability of commercial IRMS analysers capable of measuring ${ }^{2} \mathrm{H} /{ }^{1} \mathrm{H}$ ratios in the presence of a helium carrier gas. These innovations have, to a large extent, overcome the difficulties associated with offline gas preparation for DI-MS and greatly increased the applicability of this measurement. It is now possible to routinely measure ${ }^{2} \mathrm{H}$ and ${ }^{18} \mathrm{O}$ abundances in organic samples by Pyrolysis-Continuous Flow-Isotope Ratio Mass Spectrometry (Py-CF-IRMS).

Therefore, measurements of stable isotope ratios of the light elements $(\mathrm{H}, \mathrm{C}, \mathrm{N}, \mathrm{O}, \mathrm{S}$ and bioelements) and of the heavy element stronzium, in natural cycles, have provided geographical fingerprints (Roßmann et al., 2000).

Preliminary investigations into the application of ${ }^{18} \mathrm{O}$-pyrolysis continuous-flow IRMS to obtain information about the geographical origin of olive oil samples has been conducted by Angerosa et al. (1999). They measured the $\delta^{13} \mathrm{C}$ and $\delta^{18} \mathrm{O}$ values of whole olive oil, sterols and aliphatic alcohol fractions from fruits of Olea europaea L. produced in Greece, Italy, Morocco, Spain, Tunisia, and Turkey. The results permitted provincial classification of the oils. However, there were some misclassifications observed for oil samples coming from neighbouring countries with similar climates.

A secure geographical classification of an olive oil, in order to ensure that the consumer is not defrauded and that the honest trader is not disadvantaged by having their PDO oils misrepresented by inferior products, can be achieved by performing heavy isotope ratios (e.g. ${ }^{88} \mathrm{Sr} /{ }^{86} \mathrm{Sr}$ ) and multi-element analysis.

\subsubsection{Nuclear magnetic resonance spectroscopy}

During the last ten years, nuclear magnetic resonance spectroscopy (NMR) (Del Coco et al., 2012; Mannina \& Segre, 2002), has played an ever-increasing role in the study olive oil characterization and autentication. In particular, it has been shown that high-resolution NMR together with statistical analysis constitutes a powerful tool for the geographical characterization of olive oils on Mediterranean, national, regional and PDO scales. On this regard, innovative techniques like NMR spectroscopy seem to be able to distinguish olive oils on the basis of their geographical origin, whereas the conventional analyses suitable for the determination of quality and genuineness seem not to be so appropriate for this type of discrimination (Frankel, 2010; Guillen \& Ruiz, 2001).

Important information on the fatty acid distribution on the glycerol moiety can be obtained by ${ }^{13} \mathrm{C}$ NMR (Rezzi et al., 2005; Petrakis et al., 2008; Alonso-Salces et al., 2010b; Mannina et al., 2010; Alonso-Salces et al., 2011b). Two groups of resonances are observed in the carbonyl region of the ${ }^{13} \mathrm{C}$ NMR spectrum of an olive oil: one group is due to fatty chains in position sn- 1,3 of the glycerol moiety, the other one is due to fatty acids in position sn-2. 
It must be noted that although gas chromatographic methods give the full composition of fatty chains, no information is given about the fatty chains distribution on glycerol. Thus in this case, gas chromatography and ${ }^{13} \mathrm{C}$ NMR methodologies must be considered complementary and not alternative. ${ }^{13} \mathrm{C}$ NMR spectroscopy together with discriminant analysis has been proposed by Mavromoustakos et al., to detect the presence of soybean oil, cottonseed oil, corn oil and sunflower seed oil in virgin olive oils. Only double bonds signals have been used for the analysis. Fatty acids composition and fatty chain positional distribution on glycerol moiety determined by ${ }^{13} \mathrm{C}$ NMR spectroscopy allow, in combination with the multivariate statistical procedure, the classification of olive oils according to their variety (Marini et al., 2004, 2006).

${ }^{31} \mathrm{P}$ NMR spectroscopy has been employed for the detection and quantification of the minor compounds mono- and diacylglycerols, polyphenols, sterols, phospholipids and for the determination of free acidity and moisture (Petrakis et al., 2008). This analytical technique requires the derivatization of the labile hydrogens of the hydroxyl and carboxyl groups of the olive oil constituents using the phosphorous reagent 2-chloro-4,4,5,5- tetramethyl dioxaphospholane and the use of ${ }^{31} \mathrm{P}$ chemical shifts of the phosphitylated compounds to identify the labile centers. The main phospholipids found in olive oil were phosphatidic acid, lyso-phosphatidic acid and phosphatidylinosotol, although very small amounts of other phospholipids were detected as well. In this way, the content of free fatty acids has been determined showing a good correlation with official titration method. Besides, using the same derivatization method, sn-1,2, sn-1,3-diacylglycerides and monoacylglycerides have been quantified and have showed a characteristic trend during olive oil storage.

The composition of diacylglycerols (sn-1,2- 1,3-diacylglycerols and total) determined by ${ }^{31} \mathrm{P}$ NMR derivatization method has been used to characterize olive oils from different Greek areas (Petrakis et al., 2008). Some preliminary correlations between the diacylglycerols content and the geographical regions have been observed.

The geographical characterization of monovarietal virgin olive oils from three regions of Southern Greece, namely Peloponnesus, Crete and Zakynthos, has been performed applying both ${ }^{1} \mathrm{H}$ and ${ }^{31} \mathrm{P}$ NMR (Petrakis et al., 2008). The correct geographical prediction at the level of three regions, based on discriminant analysis, has been rather high (87\%). Phenolic compounds and free acidity determined by ${ }^{31} \mathrm{P}$ NMR spectroscopy have enabled to classify Koroneiki, Athinolia and Kolovi monovarietal Greek extra virgin olive oils using ANOVA and discriminant analysis.

${ }^{1} \mathrm{H}$ NMR spectrum of an olive oil does not provide this information directly; however, it is possible to have an indirect measurement of acidity using the measurable amount of diglycerides and monoglycerides.

Another study carried out by using ${ }^{1} \mathrm{H}$ NMR involved the characterization of the phenolic fraction of olive oil from three different areas of the Apulia region (Sacco et al., 2000). Statistical evaluation has showed discrimination between Coast, Hinterland and North samples. 
Extra virgin olive oils sampled in three harvesting years and coming from different Italian regions (Tuscany, Lazio, Lake of Garda) have been analyzed by ${ }^{1} \mathrm{H}$ methodology. The statistical elaboration applied on the intensity of b-sitosterol, aldehydes and some other volatile compounds has allowed the classification of the olive oils according to the geographical regions.

${ }^{1} \mathrm{H}-\mathrm{NMR}$ fingerprinting of olive oil is a valuable analytical tool for the traceability of virgin olive oils from different points of view, i.e. food authentication and food quality. As described before, ${ }^{1} \mathrm{H}$ and ${ }^{13} \mathrm{C}$ NMR techniques provide different information: ${ }^{1} \mathrm{H}$ NMR spectrum allows the measurement of minor components of olive oils such as $\beta$-sitosterol, hexanal, 2-(E)-hexenal, formaldehyde, squalene, cycloartenol and linolenic acid; the ${ }^{13} \mathrm{C}$ NMR spectrum detects major components such as glycerol tri-esters of olive oils, defining also acyl composition and positional distribution on the glycerol moiety. The main sensitivity concern about ${ }^{1} \mathrm{H}$ NMR analysis is the dynamic range, which makes the detection of signals below the threshold imposed by the ADC (analogue to digital converter) impossible. Therefore, in a standard extra virgin oil spectrum, trace component detection is limited to signals more intense than $10-5$ times the intensity of the fatty acid $\mathrm{CH}_{2}$ signals. Weak signals above the dynamic range threshold are in any case affected by severe baseline distortion. Selective pulses coupled to gradient spin-echo refocusing such as DPFGSE (69), in NMR modern instruments, allow these limitations to be circumvented, paving the way for the easy detection of minor components, especially those presenting resonances away from other interfering resonances.

The power of these new sequences could be demonstrated by the detection of aldehydes, carotenoids or other specific minor components whose resonances fall in a relatively free region. It was performed a specific DPFGSE analysis on the aldehydic components of some extra virgin olive oils, mostly responsible of the sensorial properties of extra virgin olive oil. Comparison with standard ${ }^{1} \mathrm{HNMR}$ spectra show tremendous improvement of quantitative and qualitative information with drastic instrumental time reduction.

Fingerprinting techniques such as NMR, NIR (Galtier et al., 2007; Mignani et al., 2011), MIR (Reid et al., 2006), fluorescence (Kunz et al., 2011), FT-IR, FT-MIR and FT-Raman (Baeten et al., 2005; Lopez-Diez et al., 2003; Yang et al., 2005) spectroscopies, have been used for the determination of food authenticity (Reid et al., 2006).

These types of techniques are particularly attractive since they are non selective, require little or no sample pre-treatment; use small amounts of organic solvents or reagents; and the analysis takes only a few minutes per sample.

\subsection{Molecular markers for the traceability of olive oil}

The food crisis situation seen in last years and the controversy about genetically modified organisms (GMO), with a sharp increase in basic food prices, highlights the extreme susceptibility of the current agricultural and food model and the need for more strict food quality control, which should include determination of the origin of the product and the raw 
materials used in it. That's why a well documented traceability system has become a requirement for quality control in the food chain.

Almost 84\% from the total olive oil production derives from the European Union, especially from Spain, Italy and Greece. The olive oil is a main constituent of the Mediterranean diet. However there has recently been an increase in olive oil consumption internationally, due to greater availability and the current consideration of high nutritive and health benefits, including a qualified health claim from Food and Drug Administration (FDA, USA).

Molecular markers allow the detection of DNA polymorphisms and enable to effectively distinguish different varieties in an effective way, without any environmental influence.

Olive oil extraction is the process of extracting the oil present in the olive drupes for food use. Olive oil extraction is the process of separating the oil from the other fruit contents. It is possible to attain this separation by physical means alone, i.e. oil and water do not mix, so they are relatively easy to separate. The modern method of olive oil extraction uses an industrial decanter to separate all the phases by centrifugation. In this method the olives are crushed to a fine paste. This can be done by a hammer crusher, disc crusher, depicting machine or knife crusher. This paste is then malaxed for about 30 minutes in order to allow the small olive droplets to agglomerate.

When we blend olive oils of the same category, but from different provenances, most chemical analyses are of limited significance. Due to their high variability according to environmental conditions, neither morphological characteristics of different groups, nor the analyses of chemical composition of fatty acid and secondary metabolites can provide reliable results for oil traceability (Ben Ayed et al., 2009; Papadia et al., 2011). For this reason, genetic identity seems to be the most appropriate method for identifying the variety from which the olive oil under study derives.

Molecular markers allow the detection of DNA polymorphisms and enable to effectively distinguish different varieties in an effective way, without any environmental influence. In fact, DNA in oil is not affected by the environment and is identical to the mother tree DNA since the oil containing tissues are formed by diploid somatic cells of the tree (Muzzalupo et al., 2007). However, depending on the molecular markers used correctly, extra alleles can be detected in the oil that do not correspond to the mother tree allele but to the pollinator alleles contained in the embryo, itself located inside the seed (Muzzalupo and Perri, 2002; Ben Ayed et al., 2010).

The use of DNA based technology in the field of food authenticity is gaining increasing attention. This technique makes use of molecular markers that mostly use polymerase chain reaction (PCR) and are thus easy to genotype. Even in a complex matrix such as olive oil, molecular marker techniques such as RAPDs (random amplified polymorphic DNA, Pasqualone et al., 2001; Muzzalupo and Perri, 2002).), AFLPs (amplified fragment length polymorphism, Pafundo et al., 2005; Montemurro et al., 2007) and SSRs (simple sequence repeat, Muzzalupo et al., 2007; Breton et al., 2004; Bracci et al., 2011; Ben Ayed et al., 2009) are very useful in the study of the traceability of olive oil. Single nucleotide polymorphism 
(SNPs) markers have been recently developed in olive and utilized to study the genetic diversity of olive trees (Reale et al., 2006). SNP detection can be delivered in a number of ways, but the simultaneous detection of multiple SNPs from a single DNA sample is of particular interest (Consolandi et al., 2008). PDO oils are typically not monovarietal, so a method for quantifying the components of the mixture is essential if conformity with certification depends on a prescribed proportion of varietal types. So far, application of RealTime as a tool for olive oil authentication has been explored by Giménez et al., (2010). The authors evidenced that Real-Time PCR is useful to quantify DNA extracted from oil, and thus to assess the yields of different methods of extraction. But the size of amplicon, is critical for the success of analysis. A possibility of utilising qRT-PCR to quantify varieties in PDO oils rests on the use of taqMan probes designed on SNPs specific of varieties entering in the oil composition (Marmiroli et al., 2009). Several sequences from noncoding spacer region between $p s b A-\operatorname{trn} H$ and partial coding region of matK of plastid genome provided a good discrimination of pure olive oil and its admixture by other vegetable oils such as canola and sunflower. The plastid based molecular DNA technology has a great potential to be used for rapid detection of adulteration easily up to 5\% in olive oil (Kumar et al., 2011).

The knowledge of genome nucleotide sequences also could be useful to identify new sequence polymorphisms, which will be very useful in the development of many new variety-specific molecular markers and in the implementation of more efficient protocols for tracking and protect olive oil origin.

A recent publication reported by Papadia et al., 2011 a systematic effort to obtain genetic characterization by SSR amplification, soil analyses, and 1H-NMR spectra, is carried out in order to make a direct connection between the olive tree variety (genetic information) and the NMR spectra (chemical information) of the extra virgin olive oil produced. The results reported show that a multidisciplinary approach, through the application of multivariate statistical analysis, could be used to set up a method for variety and/or geographic origin certification, based on the construction of a suitable database. Further research will be directed to the growth of an organic genetic/NMR/soil database, in order to improve the prediction ability of the LDA, and furthermore to develop a way to correlate ${ }^{1} \mathrm{H}-\mathrm{NMR}$ spectra of commercial extra virgin olive oils with their geographical and genetic origin.

\subsection{Electrochemical sensor analysis for the traceability of olive oil}

Electronic noses (e-noses) and electronic tongues (e-tongues) for liquid analysis, based on the organizational principles of biological sensory systems, developed rapidly during the last decade. E-noses and e-tongues crudely mimic the human smell and taste sensors (gas and liquid sensors) and their communication with the human brain. The human olfactory system is by far the more complex and contains thousands of receptors that bind odor molecules and can detect some odors at parts per trillion levels (Breer, 1997) and include between 10 and 100 million receptors (Deisingh et al., 2004). Apparently some of the receptors in the olfactory mucus can bind more than one odor molecule and in some cases one odor molecule can bind more than one receptor. This results in a mind-boggling amount 
of combinations that send unique signal patterns to the human brain. The brain then interprets these signals and makes a judgment and/or classification to identify the substance consumed, based in part, on previous experiences or neural network pattern recognition. The electronic nose often consists of non-selective sensors that interact with volatile molecules that result in a physical or chemical change that sends a signal to a computer which makes a classification based on a calibration and training process leading to pattern recognition. The non-selectivity of the sensors results in many possibilities for unique signal combinations, patterns or fingerprints. The human tongue contains sensors, in the form of 10,000 taste buds of 50-100 taste cells each (Deisingh et al., 2004) for sweet, sour, bitter, salty and umami and is much less complicated than the human olfactory system. The e-tongue then uses a range of sensors that respond to salts, acids, sugars, bitter compounds, etc. and sends signals to a computer for interpretation. The interpretation of the complex data sets from e-nose and e-tongue signals is accomplished by use of multivariate statistics. For nonlinear responses, artificial neural networks (NAA) can be used for modeling the data. Biosensors are also being developed, but are not yet commercialized. In contrast to chemical sensing materials, that are broad spectrum to generate characteristic response patterns, there are biological systems. The problem with chemical sensors is that these systems are extensive, require large sample sizes for analysis, have low sensitivity and poor specificity compared with the human nose. The bioelectronic nose utilizes olfactory receptors as sensing mechanisms and are cell or protein-based to mimic a mammalian olfactory system (Lee and Park, 2010). Another type of sensing system is based on colorimetric sensor array built in disposable chips (Suslick et al., 2010). These arrays are based on the chemical interactions between the analyte and a chemical dye. They are being developed for volatile and non volatile molecules (Zhang et al., 2006; Zhang and Suslick, 2007; Musto et al., 2009) for applications by the food industry.

The advantage of the human sensory system is that the brain can receive signals from both olfactory and tongue receptors and integrate both sets of data to form classifications and/or judgments. The e-nose and e-tongue are not integrated since each has its own software package, but the data from both instruments could be imported into another program and integrated. The disadvantage of the human sensory system is that no two brains are alike (of course from another point of view, this is a good thing), and the same brain may react differently from one day to the next, depending on an individual's health, mood or environment, making the data subjective. On the contrary, e-nose and e-tongue instruments can be calibrated to be reliably consistent and can give objective data for important functions like quality and safety control. These instruments can also test samples that are unfit for human consumption. A disadvantage for the e-nose and e-tongue systems (as with humans) is that they are also affected by the environment including temperature for both enose and e-tongue and humidity for e-nose, which can cause sensor drift, although calibration systems and built-in algorithms help compensate for this. There are more or at least not less different types of sensing materials for e-tongue (liquid sensors) compared to e-nose systems, and liquid sensors often possess higher selectivity and significantly lower detection limits compared to the gas sensors (e-nose). 
There are several reviews on the subject of e-nose and e-tongue technology, including reviews on e-noses (Di Giacinto et al., 2010; Wilson and Baietto, 2009), biomimetic/biotechnology e-nose and/or e-tongue sensing systems (Rudnitskaya and Legin, 2008; Ghasemi-Varnamkhasti et al., 2010)], applications for e-noses and e-tongues (Scampicchio et al., 2008), neural networks for e-noses (Lu et al., 2000), pattern recognition techniques (Berrueta et al., 2007); meat quality assessment by e-nose (GhasemiVarnamkhasti et al., 2009) and computational methods for analysis of e-nose data (Jurs et al., 2000). This review will concentrate on the recent literature on applications of e-noses and etongues in the food industry.

\section{Conclusions}

Some varieties of olive oil are recognized as being of higher quality because they derive from well-defined geographical areas, command better prices and generally are legally protected. Indeed, the aim of Protected Designations of Origin (PDO), Protected Geographical Indication (PGI) and Traditional Specialty Guaranteed (TSG) is to add value to certain specific high quality products from a particular origin.

The development of accurate analytical fingerprinting methods for the authentication of olive oils and for the certification of the geographical origin is an actual issue and an important challenge. In fact, to protect the rights of both the consumer and honest producers and, to enforce the laws, it is important to develop analytical methods to measure the authenticity of the samples, to verify the geographical or cultivar origin and to provide the presence/absence of adulterants.

\section{Author details}

Enzo Perri*, Cinzia Benincasa and Innocenzo Muzzalupo

Agricultural Research Council - Olive Growing and Oil Industry Research Centre, Rende (CS), Italy

\section{Acknowledgement}

Financial support for this study was provided by Italian Ministry of Agriculture, Food and Forestry through the project GERMOLI "Salvaguardia e valorizzazione del GERMoplasma OLIvicolo delle collezioni del CRA-OLI"

\section{References}

Alonso-Salces, R. M., Moreno-Rojas, J. M., Holland, M. V., \& Guillou, C. (2011b). Authentication of Virgin Olive Oil using NMR and isotopic fingerprinting. In series: Food Science and Technology, Nova Science Publishers, ISBN 978-1-61122-309-5, New York.

\footnotetext{
${ }^{*}$ Corresponding Author
} 
Alonso-Salces, R. M., Moreno-Rojas, J. M., Holland, M. V., Reniero, F., Guillou, C., \& Heberger, K. (2010b). Virgin Olive Oil Authentication by Multivariate Analyses of $1 \mathrm{H}$ NMR Fingerprints and $\delta 13 \mathrm{C}$ and $\delta 2 \mathrm{H}$ Data. Journal of Agricultural and Food Chemistry, Vol.58, No.9, pp. 5586-5596, ISSN 0021-8561.

Angerosa, F., Breas, O., Contento, S., Guillou, C., Reniero, F. \& Sada, E, (1999). J. Agric. Food Chem., Vol.47, pp. 1013-1017.

Aparicio, R., \& Aparicio-Ruiz, R. (2000). Authentication of vegetable oils by chromatographic techniques. Journal of Chromatography A, Vol.881, No.1-2, pp. 93104, ISSN 0021-9673.

Araghipour, N., Colineau, J., Koot, A., Akkermans, W., Rojas, J. M. M., Beauchamp, J., Wisthaler, A., Märk, T. D., Downey, G., Guillou, C., Mannina, L., van Ruth, S. (2008). Geographical origin classification of olive oils by PTR-MS. Food Chem., Vol.108, pp. 374383.

Baeten, V., Pierna, J. A. F., Dardenne, P., Meurens, M., Garcia-Gonzalez, D. L., \& AparicioRuiz, R. (2005). Detection of the presence of hazelnut oil in olive oil by FT-Raman 204 Olive Oil - Constituents, Quality, Health Properties and Bioconversions and FT-MIR spectroscopy. Journal of Agricultural and Food Chemistry, Vol.53, No.16, pp. 6201-6206, ISSN 0021-8561.

Ben Ayed, R., Grati-Kamoun, N., Moreau, F. \& Rebai, A. (2009). Comparative study of microsatellite profiles of DNA from oil and leaves of two Tunisian olive cultivars. European Food Research and Technology, Vol.229, pp. 757-762, ISSN 1438-2377.

Benincasa, C., Lewis, J., Perri, E., Sindona, G. \& Tagarelli, A. (2007), Determination of Trace Element in Italian Virgin Olive Oils and their Characterization According to Geographical Origin by Statistical Analysis. Analitica Chimica Acta, Vol.585, pp. 366-370.

Benincasa, C., De Nino, A., Lombardo, N., Perri, E., Sindona, G. \& Tagarelli, A. (2003), Assay of aroma active components of virgin olive oils from southern italian regions by SPMEGC/ion trap mass spectrometry. J. Agric. Food Chem., Vol.51, pp. 733-741.

Bracci, T.; Busconi, M.; Fogher C. \& Sebastiani L. (2011). Molecular studies in olive (Olea europaea L.): overview on DNA markers applications and recent advances in genome analysis. Plant Cell Reports, Vol.30, pp. 449-462, ISSN 0721-7714.

Breton, C.; Claux, D.; Metton, I.; Skorski, G. \& Berville, A. (2004). Comparative study of methods for DNA preparation from olive oil samples to identify cultivar SSR alleles in commercial oil samples: possible forensic applications. Journal of Agriculture and Food Chemistry, Vol.52, pp. 531-537, ISSN 0021-8561.

Bricout, J., Koziet, J. (1987). Control of the authenticity of orange juice by isotopic analysis. J. Agric. Food Chem., Vol.35, pp. 758-760.

Canabate-Diaz, B., Segura Carretero, A., Fernandez-Gutierrez, A., Belmonte Vega, A., Garrido Frenich, A., Martinez Vidal, J. L., \& Duran Martos, J. (2007). Separation and determination of sterols in olive oil by HPLC-MS. Food Chemistry, Vol.102, No.3, pp. 593-598, ISSN 0308-8146.

Cavaliere B., De Nino A., Hayet F., Lazez A., Macchione B., Moncef C., Perri E., Sindona G., Tagarelli A.(2007), A metabolomic approach to the evaluation of the origin of extra 
virgin olive oil: a conventional statistical treatment of mass spectrometric analytical data. J. Agric. Food Chem., Vol.55, pp. 1454-1462.

Cindric, I. J., Zeiner, M., \& Steffan, I. (2007), Trace elemental characterization of edible oils by ICP-AES and GFAAS. Microchemical Journal, 85, 136-139. doi:10.1016/j.microc.2006.04.011.

Commission Regulation (EC) No. 178/2002 of the European Parliament and of the Council of 28 January 2002 laying down the general principles and requirements of food law, establishing the European Food Safety Authority and laying down procedures in matters of food safety.

Commission Regulation (EC) No. 182/2009 of 6 March 2009 amending Regulation (EC) No 1019/2002 on marketing standards for olive oil.

Consolandi, C., Palmieri, L., Severgnini, M., Maestri, E.. Marmiroli, N., Agrimonti, C., Baldoni, L., Donini, P., Bellis, G. \& Castiglioni, B. (2008). A procedure for olive oil traceability and authenticity: DNA extraction, multiplex PCR and LDR-universal array analysis. European Food Research and Technology, Vol.227, pp. 1429-1438, ISSN 1438-2377.

Council Regulation (EEC) No. 2081/92 on the protection of geographical indications and designations of origin for agricultural products and foodstuffs. Off. J. European Union 1992, L 208, 1-15.

Culp, R. A., Noakes, J. E. (1990). Identification of isotopically manipulated cinnamic aldehyde and benzaldehyde. J. Agric. Food Chem., Vol.38, pp. 1249-1255.

Del Coco, L., Schema, F. P. \& Fanizzi, F. P. (2012). 1H Nuclear Magnetic Resonance Study of Olive Oils Commercially Available as Italian Products in the United States of America. Nutrients, Vol. 4(5), pp. 343-355; doi:10.3390/nu4050343

Di Donna, L., De Nino, A., Mazzotti, F., Perri E., Raffaelli, A., \& Sindona, G. (2001). Quantitative determination of oleuropein in organic olive oil. In Biologically-active Phytochemicals in Food (a cura di), Cambridge: Royal society of chemistry, pp. 131-132.

Sindona, G., Perri, E., Mazzotti, F., \& Raffaelli, A. (2000). High-throughput screening of tocopherols in natural extracts". J. Mass Spectr, Vol. 35, pp. 1360-1361.

Sindona, G., De Nino, A., Mazzotti, F., Perri, E., Procopio, A., \& Raffaelli, A. (2000). Virtual Freezing of the Hemiacetal-Aldehyde Equilibrium of the Aglycones of Oleuropein and Ligstroside present in olive oils from Carolea and Coratina Cultivars by Ion-spray Ionisation Tandem Mass Spectrometry. J. Mass Spectr., Vol.35, pp. 461-467.

Kelly, S. D., Parker, I., Sharman, M. and Dennis, M. J. (1997) Assessing the authenticity of single seed vegetable oils using fatty acid stable carbon isotope ratios (13C/12C), Food Chemistry, Vol.2, pp. 181-186.

Berrueta, L. A., Alonso-Salces, R. M. \& Heberger, K. (2007). Supervised pattern recognition in food analysis. J. Chromatogr. A, Vol.1158, pp. 196-214.

Breer, H. (1997). Sense of smell: Signal recognition and transductions in olfactory receptor neurons. In Handbook of Biosensors and Electronic Noses: Medicine, Food and Environment; Kress-Rogers, E., Ed.; CRC Press: Boca Raton, FL, USA, 1997; pp. 521-532.

Deisingh, A. K., Stone, D. C. \& Thompson, M. (2004). Applications of electronic noses and tongues in food analysis. Int. J. Food Sci. Technol, Vol.39, pp. 587-604. 
Dugo, G., La Pera, L., Giuffrida, D., Salvo, F., Lo Turco, V. (2004), Influence of the olive variety and the zone of provenience on selenium content determined by cathodic stripping potentiometry (CSP) in virgin olive oils. Food Chemistry, Vol.88, pp. 135-140. doi:10.1016/j.foodchem.2003.12.036.

Di Giacinto, L., Di Loreto, G., Di Natale, C., Gianni, G., Guasti, S., Migliorini, M., Pellegrino, M., Perri, E., Santonico, M., 2010, Caratterizzazione analitica degli attributi sensoriali degli oli vergini di oliva, Ed. Camera di Commercio di Firenze.tività Dunbar, J. \& Schmidt, H-L. (1984). Measurement of the $2 \mathrm{H} / 1 \mathrm{H}$ ratios of the carbon bound hydrogenatoms in sugars. Fres, Z. Anal. Chem., Vol.317, pp. 853-857.

Frankel, E. N. (2010). Chemistry of extra virgin olive oil: Adulteration, oxidative stability, and antioxidants. Journal of Agricultural and Food Chemistry, Vol.58, No.10, pp. 59916006, ISSN 0021-8561.

Galtier, O., Dupuy, N., Le Dréau, Y., Ollivier, D., Pinatel, C., Kister, J., \& Artaud, J. (2007). Geographic origins and compositions of virgin olive oils determinated by chemometric analysis of NIR spectra. Analytica Chimica Acta, Vol.595, No.1-2, pp. 136-144, ISSN 0003-2670.

Ghasemi-Varnamkhasti, M., Mohtasebi, S. S. \& Siadat, M. (2010). Biomimetic-based odor and taste sensing systems to food quality and safety characterization: An overview on basic principles and recent achievements. J. Food Eng., Vol.100, pp. 377-387.

Ghasemi-Varnamkhasti, M., Mohtasebi, S. S., Siadat, M. \& Balasubramanian, S. (2009). Meat quality assessment by electronic nose (Machine Olfaction Technology). Sensors, Vol.9, pp. 6058-6083.

Giménez, M.J.; Pistón, F.; Martín, A. \& Atienza, G.S. (2010). Application of real-time PCR on the development of molecular markers and to evaluate critical aspects for olive oil authentication. Food Chemistry, Vol.118, pp. 482-487, ISSN 0308-8146.

Guillen, M. D., \& Ruiz, A. (2001). High resolution H-1 nuclear magnetic resonance in the study of edible oils and fats. Trends in Food Science \& Technology, Vol.12, No.9, pp. 328-338, ISSN 0924-2244.

Haddada, F. M., Manai, H., Daoud, D., Fernandez, X., Lizzani-Cuvelier, L., \& Zarrouk, M. (2007). Profiles of volatile compounds from some monovarietal Tunisian virgin olive oils. Comparison with French PDO. Food Chemistry, Vol.103, No.2, pp. 467- 476, ISSN 0308-8146

Harwood, J. \& Sánchez, J. (1999). Lipid biosynthesis in olives in Handbook of olive oil, p. 129-158. J. Harwood \& R. Aparicio (Eds.), Aspen publisher Inc., Maryland, USA.

Howarth, O. W., \& Vlahov, G. (1996). C-13 Nuclear -Magnetic-Resonance study of cyclopropenoid triacylglycerols. Chemistry and physics of lipids, Vol.81, no.1, pp. 81-85.

Japon-Lujan, R., Luque-Rodriguez, J. M. \& Luque de Castro, M. D. (2006). Dynamic ultrasound-assisted extraction of oleuropein and related biophenols from olive leaves. $J$. Chrom. A, Vol.1108, pp. 76-82.

Jurs, P. C., Bakken, G. A. \& McClelland, H. E. (2000). Computational methods for the analysis of chemical sensor array data from volatile analytes. Chem. Rev., Vol.100, pp. 2649-2678. 
Kiritsakis, A. \& Christie, W. W. (1999). Analysis of edible oils in Handbook of olive oil, p. 129-158. J. Harwood \& R. Aparicio (Eds.), Aspen publisher Inc., Maryland, USA

Kumar, S.; Kahlon, T. \& Chaudhary, S. (2011). A rapid screening for adulterants in olive oil using DNA barcodes, Food Chemistry. Vol.127, pp. 1335-1341, ISSN 0308-8146.

Kunz, M. R., Ottaway, J., Kalivas, J. H., Georgiou, C. A., \& Mousdis, G. A. (2011). Updating a synchronous fluorescence spectroscopic virgin olive oil adulteration calibration to a new geographical region. Journal of Agricultural and Food Chemistry, Vol.59, No.4, pp. 1051-1057, ISSN 1520-5118.

Lanteri S., Armanino C., Perri E., Palopoli A. (2002). Study of oils from calabrian olive cultivars by chemometric methods. Food Chemistry, Vol.76, pp. 501-507.

Lanteri, S., Armanino, C., Perri, E., \& Palopoli, A. (2002). Study of oils from Calabrian olive cultivars by chemometric methods. Food Chemistry, Vol.76, No.4, pp. 501-507, ISSN 0308-8146.

Lazzez, A., Perri, E., Caravita, M. A., Khlif, M., and Cossentini, M. (2008). Influence of Olive Maturity Stage and Geographical Origin on Some Minor Components in Virgin Olive Oil of the Chemlali Variety. J. Agric. Food Chem., Vol.56, pp. 982-988.

Lee, S. \& Park, T. (2010). Recent advances in the development of bioelectronic nose. Biotechnol. Bioprocess Eng., Vol.15, pp. 22-29.

Lopez Ortiz, C. M., Prats Moya, M. S., \& Berenguer Navarro, V. (2006). A rapid chromatographic method for simultaneous determination of -sitosterol and tocopherol homologues in vegetable oils. Journal of Food Composition and Analysis, Vol.19, No.23, pp. 141-149, ISSN 0889-1575.

Lu, Y., Bian, L. \& Yang, P. (2000). Quantitative artificial neural network for electronic noses. Anal. Chim. Acta, Vol.417, pp. 101-110.

Mannina, L., \& Segre, A. (2002). High resolution nuclear magnetic resonance: From chemical structure to food authenticity. Grasas y Aceites, Vol.53, No.1, pp. 22-33, ISSN 0017-3495.

Mannina, L., Marini, F., Gobbino, M., Sobolev, A. P., \& Capitani, D. (2010). NMR and chemometrics in tracing European olive oils: the case study of Ligurian samples. Talanta, Vol.80, No.5, pp. 2141-2148, ISSN 1873-3573.

Marini, F., Balestrieri, F., Bucci, R., Magrì, A. D., Magrì, A. L., \& Marini, D. (2004). Supervised pattern recognition to authenticate Italian extra virgin olive oil varieties. Chemometrics and Intelligent Laboratory Systems, Vol.73, No.1, pp. 85-93, ISSN 01697439 .

Marini, F., Magrì, A. L., Bucci, R., Balestrieri, F., \& Marini, D. (2006). Class-modeling techniques in the authentication of Italian oils from Sicily with a Protected Denomination of Origin (PDO). Chemometrics and Intelligent Laboratory Systems, Vol.80, No.1, pp. 140-149, ISSN 0169-7439.

Marmiroli, N.; Maestri, E.; Pafundo. S. \& Vietina, M. (2009). Molecular traceability of olive oil: from plant genomics to Food Genomics. In: Berti L, Maury J (eds) Advances in olive resources. Research Signpost, pp. 1-16, ISBN 978-81-7895-388-5, Kerala, India.

Mavromoustakos, T., Zervou, M., Bonas, G., Kolocouris, A., \& Petrakis, P. (2000). J. Am. Oil Chem. Soc., Vol. 77, pp. 405-411. 
Mignani, A. G., Ciaccheri, L., Ottevaere, H., Thienpont, H., Conte, L., Marega, M., Cichelli, A., Attilio, C., \& Cimato, A. (2011). Visible and near-infrared absorption spectroscopy by an integrating sphere and optical fibers for quantifying and discriminating the adulteration of extra virgin olive oil from Tuscany. Analytical and Bioanalytical Chemistry, Vol.399, No.3, pp. 1315-1324, ISSN 1618-2650.

Montealegre, C, Marina Alegre, M. L., García-Ruiz, C. (2010). Traceability markers to the botanical origin in olive oils. J Agric Food Chem. Vol.58, no.1, pp. 28-38.

Montemurro, C.; Pasqualone, A.; Simeone, R.; Sabetta, W. \& Blanco, A. (2007). AFLP molecular markers to identify virgin olive oils from single Italian cultivars. European Food Research and Technology, Vol.226, pp. 1439-1444, ISSN 1438-2377.

Musto, C. J., Lim, S. H. \& Suslick, K. S. (2009). Colorimetric detection and identification of natural and artificial sweeteners. Anal. Chem., Vol.81, pp. 6526-6533.

Muzzalupo, I. \& Perri, E. (2002). Recovery and characterization of DNA from virgin olive oil. European Food Research and Technology, Vol.214, pp. 528-531, ISSN 1438-2377.

Muzzalupo, I.; Pellegrino, M. \& Perri, E. (2007). Detection of DNA in virgin olive oils extracted from destoned fruits. European Food Research and Technology, Vol.224, pp.469475, ISSN 1438-2377.

O'Leary MH (1981). Carbon siotope fractionation in plants, Phytochemistry, Vol.20, pp. 553567.

Pafundo, S.; Agrimonti, C. \& Marmiroli, N. (2005). Traceability of plant contribution in olive oil by amplified fragment length polymorphisms. Journal of Agricultural and Food Chemistry, Vol.53, pp. 6995-7002, ISSN 0021-8561.

Papadia, P.; Del Coco, L.; Muzzalupo, I.; Rizzi, M.; Perri, E.; Cesari, G.; Simeone, V.; Mondelli, F.; Schena, F.P. \& Fanizzi, F.P. (2011). Multivariate analysis of 1H-NMR spectra of genetically characterized extra virgin olive oils and growth soil correlations. Journal of the American Oil Chemists Society, Vol.88, N. 10, pp. 1463-1475, ISSN 0003-021X.

Parker, I G., Kelly, S.D., Sharman, M., Dennis M.J., \& Howie D. (1998) Investigation into the use of Stable Carbon Isotope Ratios (13C/12C) of Scotch Whisky Congeners to establish Brand Authenticity. Food Chem., Vol.63, pp. 423-428.

Pasqualone, A.; Caponio, F. \& Blanco, A. (2001). Inter-simple sequence repeat DNA markers for identification of drupes from different Olea europaea L. cultivars. European Food Research and Technology, Vol.213, pp. 240-243, ISSN 1438-2377.

Petrakis, P. V., Agiomyrgianaki, A., Christophoridou, S., Spyros, A., \& Dais, P. (2008). Geographical characterization of Greek virgin olive oils (cv. Koroneiki) using ${ }^{1} \mathrm{H}$ and ${ }^{31} \mathrm{P}$ NMR fingerprinting with canonical discriminant analysis and classification binary trees. Journal of Agricultural and Food Chemistry, Vol.56, No.9, pp. 3200-3207, ISSN 00218561.

Reale, S.; Doveri, S.; Díaz, A.; Angiolillo, A.; Lucentini, L.; Pilla, F.; Martín, A.; Donini, P. \& Lee, D. (2006). SNP-based markers for discriminating olive (Olea europaea L.) cultivars. Genome, Vol.15, pp. 1193-1209, ISSN 0831-2796.

Reid, L. M., O'Donnell, C. P., \& Downey, G. (2006). Recent technological advances for the determination of food authenticity. Trends in Food Science \& Technology, Vol.17, No.7, pp. 344-353, ISSN 0924-2244. 
Rezzi, S., Axelson, D. E., Heberger, K., Reniero, F., Mariani, C., \& Guillou, C. (2005). Classification of olive oils using high throughput flow $1 \mathrm{H}-\mathrm{NMR}$ fingerprinting with principal component analysis, linear discriminant analysis and probabilistic neural networks. Analytica Chimica Acta, Vol.552, No.1-2, pp. 13-24, ISSN 0003-2670.

Roßmann, A. (2001). Private communication from Dr Andreas Roßmann Technical University of Munich, FRG.

Rossmann, A., Haberhauer, G., Holzl, S., Horn, P., Pichlmayer, F. \& Voerkelius, S. (2000). The potential of multielement stable isotope analysis for regional origin assignment of butter. Eur. Food Res. Technol., 211, 32-40.

Royer, A., Gerard, C., Naulet, N., Lees, M. \& Martin G. J. (1999) Stable isotope characterization of olive oils. I - Compositional and carbon-13 profiles of fatty acids. JAOCS., Vol.76, pp. 357-363.

Rudnitskaya, A. \& Legin, A. (2008). Sensor systems, electronic tongues and electronic noses, for the monitoring of biotechnological processes. J. Ind. Microbiol. Biotechnol., Vol.35, pp. 443-451.

Sacco, A., Brescia, M. A., Liuzzi, V., Reniero, F., Guillou, C., Ghelli, S., \& van der Meer, P. (2000). Characterization of Italian olive oils based on analytical and nuclear magnetic resonance determinations. JAOCS, Vol.77, No.6, pp. 619-625, ISSN 0003-021X.

Sanz-Cortes, F., Parfitt, D. E., Romero, C., Struss, D., Llacer, G. \& Badenes, M. L. (2003). Intraspecific olive diversity assessed with AFLP. Plant Breeding, Vol.122, no.2, pp. 173177.

Scampicchio, M., Ballabio, D., Arecchi, A., Cosio, S. M. \& Mannino, S. (2008). Amperometric electronic tongue for food analysis. Microchim. Acta, Vol.163, pp. 11-21.

Shaw, A. D., di Camillo, A., Vlahov, G., Jones, A., Bianchi, G., Rowland, J., \& Kell, D. B. Anal. Chim. Acta, 1997, Vol.348, pp. 357-374.

Suslick, B. A., Feng, L. \& Suslick, K. S. (2010). Discrimination of complex mixtures by a colorimetric sensor array: Coffee aromas. Anal. Chem., Vol.82, pp. 2067-2073.

Temime, S. B., Campeol, E., Cioni, P. L., Daoud, D., \& Zarrouk, M. (2006). Volatile compounds from Chétoui olive oil and variations induced by growing area. Food Chemistry, Vol.99, No.2, pp. 315-325, ISSN 0308-8146.

Vichi, S., Pizzale, L., Conte, L. S., Buxaderas, S., \& López-Tamames, E. (2005). Simultaneous determination of volatile and semi-volatile aromatic hydrocarbons in virgin olive oil by headspace solid-phase microextraction coupled to gas chromatography/mass spectrometry. Journal of Chromatography A, Vol.1090, No.1-2, pp. 146-154, ISSN 00219673.

Vichi, S.; Pizzale, L.; Conte, L. S.; Buxaderas, S.; Lopez-Tamames, E. J. Agric. Food Chem. 2003, 51, 6572-6577.

Weber, D., Kexel, H. \& Schmidt, H-L. (1997). 13C-pattern of natural glycerol: Origin and practical importance. J. Agric. Food Chem., Vol.45, pp. 2042-2046.

White, J.; Winters, K.; Martin, P. (1998) Stable carbon isotope ratio analysis of honey: Validation of internal standard procedure for worldwide application. JAOAC. Int., Vol.81, pp. 610-619. 
Wilson, A. \& Baietto, M. (2009). Applications and advances in electronic-nose technologies. Sensors, Vol.9, pp. 5099-5148.

Woodbury, S. E., Evershed, R. P. \& Rossell, J. B. (1998) $\delta^{13}$ C analyses of vegetable oil fatty acid components, determined by gas chromatography-combustionisotope ratio mass spectrometry, after saponification or regiospecific hydrolysis. J. Chromatography, Vol.805, p. 249.

Yang, H., Irudayaraj, J., \& Paradkar, M. M. (2005). Discriminant analysis of edible oils and fats by FTIR, FT-NIR and FT-Raman spectroscopy. Food Chemistry, Vol.93, No.1, pp. 25-32, ISSN 0308-8146.

Zhang, C. \& Suslick, K. S. (2007). Colorimetric sensor array for soft drink analysis. J. Agr. Food Chem.,Vol. 55, pp. 237-242.

Zhang, C., Bailey, D. P. \& Suslick, K. S. (2006). Colorimetric sensor arrays for the analysis of beers: A feasibility study. J. Agr. Food Chem., Vol. 54, pp. 4925-4931. 